\title{
Impact of p38 MAP Kinase Inhibitors on LPS-Induced Release of TNF- $\alpha$ in Whole Blood and Primary Cells from Different Species
}

\author{
Sarah Fehra Anke Unger ${ }^{b}$ Elke Schaeffelera Sonja Herrmann ${ }^{c}$ Stefan Laufer \\ Matthias Schwab ${ }^{a, d}$ Wofgang Albrecht ${ }^{b}$ \\ aDr Margarete Fischer-Bosch-Institute of Clinical Pharmacology, Stuttgart and University Tuebingen, \\ ${ }^{b} \mathrm{c}$-a-i-r biosciences $\mathrm{GmbH}$, Tuebingen, 'Department of Pharmaceutical and Medicinal Chemistry, \\ Institute of Pharmacy, University of Tuebingen, Tuebingen, 'Department of Clinical Pharmacology, \\ Institute of Experimental and Clinical Pharmacology and Toxicology, University Hospital, Tuebingen, \\ Germany
}

\section{Key Words}

p38 MAP • Kinase TNF- $\alpha \cdot$ Species Differences $•$ Whole Blood

\begin{abstract}
Background/Aims: Inhibition of p38 mitogen-activated protein kinase (p38 MAPK) is promising for the treatment of inflammatory disorders, however, the efficacy of p38 MAPK inhibitors in clinical trials is limited so far. Since functional sensitivity of p38 MAPK is commonly predicted by preclinical species, we systematically investigated interspecies differences including human tissue. Methods: Ex vivo test models were established using whole blood and primary cells from different species such as mice, rats, pigs and humans to compare LPSinduced TNF- $\alpha$ inhibition of four different p38 MAPK reference inhibitors SB 203580, BIRB796, Pamapimod, and a Losmapimod analogue as well as a proprietary imidazole-based p38 MAPK Inhibitor. Results: All analysed p38 MAPK inhibitors resulted in significant inhibition of LPS-induced TNF- $\alpha$ release but with high interspecies differences for dose sensitivity. IC $_{50}$ values from human whole blood and PBMC showed significant higher sensitivity towards p38 MAPK inhibition compared with data from pig and rat. Conclusion: Inhibition of TNF- $\alpha$ release by p38 MAPK inhibitors can be reliably identified in well-established laboratory species such as rat or mouse. However, our data indicate that animal models appear to be limited for valid prediction of the inhibitory potential for TNF- $\alpha$ release in humans. Thus, human tissues should be considered early in the drug development process of p38 MAPK inhibitors.
\end{abstract}

S. Fehr and A. Unger contributed equally.

Prof. Dr. Matthias Schwab and Dr. Wolfgang Albrecht

KARGER 125
Department of Clinical Pharmacology, University of Tuebingen, Auf der Morgenstelle 8, 72076 Tuebingen (Germany); and c-a-i-r biosciences GmbH, Paul-Ehrlich-Straße 15, 72076 Tuebingen (Germany)

E-Mail matthias.schwab@med.uni-tuebingen.de and E-Mail w.albrecht@cair-biosciences.de 


\section{Introduction}

The p38 $\alpha$ MAP kinase (MAPK) was identified as a key enzyme involved in the regulation of pro-inflammatory cytokines, when inhibitors of the enzyme blocked the release of TNF- $\alpha$ and IL-1 $\beta$ in lipopolysaccharide (LPS) stimulated monocytes [1]. Based on this observation, the drug-mediated inhibition of the p38 MAPK signalling pathway was considered as promising for the treatment of inflammatory disorders [2]. Further, elevated levels of activated p38 $\alpha$ MAPK in inflamed tissue of patients with rheumatoid arthritis (RA) [3], Crohn's disease (CD) [4] and chronic obstructive pulmonary disease (COPD) [5] confirmed these key signalling molecules as therapeutic targets. Moreover, various disorders were connected with p38 MAPK signalling pathway such as artheriosclerosis [6, 7] (via increased production of proinflammatory cytokines induced by oxidized low-density lipoprotein in human mast cell line and by inhibition of the formation of human macrophage-derived foam cells), platelet activation and thrombus formation [8] (through abrogation of p38 MAPKdependent phosphorylation of platelet cytosolic phospholipase A2), diabetic peripheral neuropathy [9] (by activated CD8(+)-T-cells mediating cytotoxicity toward Schwann cells), periodontal disease [10] (via modulation of CC chemokine ligand 11 (CCL11) related Th2 cells migration in human gingival fibroblasts), inflammation in human pulmonary epithelial cells [11] (through TNF- $\alpha$ triggered chemokine CXCL1 release) and induced proinflammatory cytokines production in macrophages [12] (via IL-17A). However, up to now, several generations of p38 MAP kinase inhibitors failed in clinical trials predominantly due to lack of efficacy and/or a poor safety profile [13-15].

During the preclinical drug development process promising candidates are selected based on the results of different test systems. First, an in vitro enzyme activity assay measures the inhibitory effect of a compound on the isolated p38 $\alpha$ enzyme [16]. Next, cellbased inflammation models using whole blood or cell culture ex vivo stimulation by LPS assess the potency in a more physiological environment [17]. These models include assay of plasma protein binding, which was shown to be important for the potency of p38 MAPK inhibitors [18].

In addition, the potential of p38 MAPK inhibitors to influence human disease progression is suggested by their efficacy in rodent disease models $[19,20]$. For example, effects of Pamapimod, a discontinued drug candidate from Roche Pharmaceuticals, on acute inflammation were shown by evaluating LPS-induced cytokine production in rodents, bone protection in a murine collagen-induced arthritis model and inflammatory pain in a rat model of hyperalgesia [21]. Despite these encouraging preclinical results, in a recent phase II trial of Pamapimod in patients with RA, liver and central nervous system side effects were reported, nevertheless $[8,22]$.

Concerning the latest generation of clinical candidates, data on species-specific antiinflammatory activities of p38 MAPK inhibitors are rare. Only one study revealed a strong species-dependent TNF- $\alpha$ inhibition by the first generation inhibitors RWJ 67657 and SB 203580 in PBMCs. The concentrations for halfmaximum inhibition ( $\mathrm{IC}_{50}$ values) in rat PBMCs were calculated as 100-fold (RWJ 67658) and as 180-fold (SB 203580) higher compared to human PBMCs [23]. Such pronounced interspecies differences are not only relevant for the extrapolation of efficacy data from experimental disease models to the clinics but may also be important for the assessment of the safety margin of clinical candidates.

Therefore, the aim of the current study was to compare the effect of several known p38 MAPK inhibitors (SB 203580, BIRB-796, Pamapimod and Losmapimod analogue) and a novel p38 MAPK inhibitor (CBS-3835) in whole blood and cell stimulations of rat, mouse, pig and human species. The candidates were selected based on chemical diversity, reported potency, selectivity and enzyme interaction (Fig. 1). SB 203580 is one of the prototype pyridinyl-imidazole based p38 $\alpha$ MAP kinase inhibitors originally developed by Smith-KlineBeecham and is widely used as an ATP-competitive reference inhibitor in the literature [24]. The Losmapimod analogue originates from a follow-up p38 $\alpha$ MAP kinase inhibitor program based on biphenyl amide or bicyclic nicotine-amide scaffolds. Another analogue of 


\section{Cellular Physiology Cell Physiol Biochem 2015;36:2237-2249

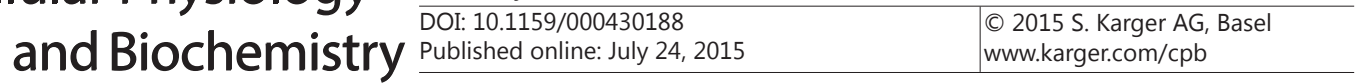 \\ Fehr et al.: Species-Specific Cell Assays for p38 MAPK Inhibitor Testing}

this series, Losmapimod (GW-856553, GSK-AHAB), is currently undergoing clinical trials for RA [25], COPD [26], cardiovascular diseases [27] and neuropathic pain [28]. BIRB-796, also known as Doramapimod, is a pyrazol-urea based p38 $\alpha$ MAP kinase inhibitor developed by Boehringer Ingelheim. BIRB-796 was reported to interact with an allosteric binding site of the enzyme requiring conformational change [29]. Thus, BIRB-796 exhibits slower binding kinetics compared to ATP-competitive inhibitors [30]. BIRB-796 underwent several clinical trials but was withdrawn from further development. Pamapimod (RO-4402257, R1503), which was developed by Roche, belongs to the class of pyrido-pyrimidone-based p38 $\alpha$ MAP kinase inhibitors. The compound was in phase II clinical development for RA [31]. Finally, with CBS-3835, a proprietary p38 $\alpha$ MAP kinase inhibitor based on the pyridinyl-imidazole scaffold, was also included in the study.

We present evidence, that p38 MAPK inhibitors are less efficient in rodents, suggesting the conclusion that data from animal experiments are not predictive for the human system.

\section{Materials and Methods}

Chemicals and test compounds

SB 203580 (4-(4-fluorophenyl)-2-(4-methylsulfinylphenyl)-5-(4-pyridyl)-1H-imidazole; CAS 152121-47-6), Losmapimod analogue (6-(3-fluoro-5-(isoxazol-3-ylcarbamoyl)-2-methylphenyl)- $N$ neopentylnicotinamide; CAS 917223-75-7), BIRB-796 (1-(5-tert-Butyl-2-p-tolyl-2H-pyrazol-3-yl)-3[4-(2-morpholin-4-yl-ethoxy)-naphthalen-1-yl]-urea; CAS 285983-48-4; Doramapimod), Pamapimod (6-(2,4-Difluoro-phenoxy)-2-[3-hydroxy-1-(2-hydroxy-ethyl)-propylamino]-8-methyl-8H-pyrido[2,3-d] pyrimidin-7-one; CAS 449811-01-2) and CBS-3835 (4-(4-(4-fluorophenyl)-2-(methylsulfonyl)-1 $H$ imidazol-5-yl)- $N$-(tetrahydro-2H-pyran-4-yl)pyridin-2-amine; CAS1009308-55-7) were synthesized at the University of Tuebingen, Department of Pharmaceutical and Medicinal Chemistry. The structures of the synthesized compounds were verified by mass spectrometry (MS) and nuclear magnetic resonance (NMR) spectroscopy. The purity of all compounds was $>99 \%$ as determined by high performance liquid chromatography (HPLC). Test compounds were dissolved in 100\% Dimethylsulfoxide (DMSO) to yield a $10 \mathrm{mM}$ stock solution. Serial dilutions were prepared using Dulbecco's phosphate buffered saline (DPBS buffer).

Unless stated otherwise, all chemicals and reagents were purchased from Sigma-Aldrich (Taufkirchen, Germany).

p38 $\alpha$ MAP kinase assay

Inhibition of p38 $\alpha$ MAP kinase activity was determined according to Laufer et al. [9] with slight modifications. In brief, the kinase reaction was carried out in 96-well microtiter plates (Immulon HBX, Thermo Fisher Scientific, Dreieich, Germany) coated with ATF-2 (Activating transcription factor-2; $6.4 \mu \mathrm{g} /$ $\mathrm{ml}$ in $0.1 \mathrm{M} \mathrm{Na}_{2} \mathrm{CO}_{3} \mathrm{pH}$ 9.5; provided by University of Tuebingen) at $4{ }^{\circ} \mathrm{C}$ overnight. After washing with TBS-T (Tris-buffered saline and Tween 20) plates were subsequently blocked with blocking buffer (1\% BSA (bovine serum albumin) in TBS-T) for $1 \mathrm{~h}$ at room temperature. Plates were washed again and $50 \mu \mathrm{l}$ of the assay mixture was added into the wells. Each assay mixture contained kinase buffer $(50 \mathrm{mM}$ Tris- $\mathrm{HCl}$ pH 7.5, $10 \mathrm{mM} \mathrm{MgCl}_{2}, 10 \mathrm{mM} \beta$-Glycerophosphat, $100 \mu \mathrm{g} / \mathrm{ml}$ BSA, 1 mM DTT (Dithiothreitol), $100 \mu \mathrm{M}$ rATP, $100 \mu \mathrm{M} \mathrm{Na}_{3} \mathrm{VO}_{4}$ ) supplemented with various concentrations of test compounds as well as human phosphop38 $\alpha$ MAP kinase (241 ng/ml, provided by Prof. Dr. J. Schultz, University of Tuebingen, Germany) and the reaction was allowed to proceed for $1 \mathrm{~h}$ at $37^{\circ} \mathrm{C}$. After subsequent washing a mouse monoclonal antiphospho-ATF-2 (pThr ${ }^{69,71}$ ) antibody (1:2000) was added into the wells, plates were incubated for $1.5 \mathrm{~h}$ at room temperature and then washed again followed by consecutive incubation with a goat anti-mouse IgGHRP antibody (1:4000) for $40 \mathrm{~min}$ at room temperature. Finally, $100 \mu \mathrm{l} \mathrm{TMB} \mathrm{(Tetramethylbezidine)} \mathrm{solution}$ (BioFX, NatuTec, Frankfurt, Germany) were pipetted into each well and plates were incubated for 15 min in the dark. Colour development was measured after addition of $50 \mu \mathrm{L}$ of $1 \mathrm{M} \mathrm{H}_{2} \mathrm{SO}_{4}$ with an enzyme-linked immunosorbent assay (ELISA) reader at $450 \mathrm{~nm}$. All samples were assayed in triplicates. 


\section{Cellular Physiology Cell Physiol Biochem 2015;36:2237-2249 \begin{tabular}{ll|l} 
and Biochemistry & $\begin{array}{l}\text { DOI 10.1159/000430188 } \\
\text { Published online: July 24, } 2015\end{array}$ & $\begin{array}{l}\text { O 2015 S. Karger AG, Basel } \\
\text { www.karger.com/cpb }\end{array}$ \\
\cline { 2 - 3 }
\end{tabular} \\ Fehr et al.: Species-Specific Cell Assays for p38 MAPK Inhibitor Testing}

\section{Stimulation of whole blood from different species}

Whole blood from healthy human volunteers was collected by venipuncture into $\mathrm{K}_{3}$-EDTA tubes and diluted with an equal volume of DPBS supplemented with gentamicin $(0.25 \mathrm{mg} / \mathrm{ml})$ prior to use. For collection of rat whole blood two male and two female Lewis rats (6 weeks, Synovo GmbH Tuebingen, Germany) were sacrificed, blood was obtained by cardiac puncture, transferred into heparinized tubes and used undiluted. Whole blood from three young male and one female German landrace pigs (body weight approx. $40 \mathrm{~kg}$, University of Ulm, Germany) was collected into heparinized tubes and used undiluted. Blood samples were kept at room temperature for 1-2 $\mathrm{h}$ until LPS stimulation. To this end, $400 \mu \mathrm{l}$ whole blood or blood diluted with DPBS was pipetted into plastic tubes preloaded with $50 \mu \mathrm{l}$ of test compound solutions at concentrations ranging from $0.001 \mu \mathrm{M}$ to $10 \mu \mathrm{M}$ (final DMSO concentration $0.1 \%$ ) and pre-incubated for 15 min at $37^{\circ} \mathrm{C}$ in a highly humidified atmosphere containing $5 \% \mathrm{CO}_{2}$. Blood was then stimulated by addition of $50 \mu \mathrm{l}$ LPS dissolved in phosphate-buffered saline (PBS; human blood: $1 \mu \mathrm{g} / \mathrm{ml}$ LPS E.coli serotype 026:B6, porcine blood: $25 \mu \mathrm{g} / \mathrm{ml}$ LPS E. coli serotype 0111:B4, rat blood: $10 \mu \mathrm{g} / \mathrm{ml}$ LPS Salmonella enterica serotype abortus equi) and samples were incubated for $2 \mathrm{~h}$ (rat whole blood) and $4 \mathrm{~h}$ (human and porcine blood), respectively. To stop the reaction, $500 \mu \mathrm{l}$ of cold DPBS buffer were added, the samples were mixed carefully and centrifuged at $600 \mathrm{xg}$ at $4{ }^{\circ} \mathrm{C}$ for $6 \mathrm{~min}$.

For the rat whole blood assay, all volumes were reduced by half since the total amount of available blood volume per rat was $<10 \mathrm{ml}$. TNF- $\alpha$ concentration in the supernatants were either immediately quantified by ELISA or stored at $-80^{\circ} \mathrm{C}$ pending analysis. Samples without addition of LPS were used as basal values and LPS controls without compound addition served as stimulation values.

For preliminary experiments, stimulation was performed with LPS from $E$ coli. serotype 026:B6, 0111:B4 as well as LPS from Salmonella enterica serotype abortus equi at final concentrations ranging from 1 to $25 \mu \mathrm{g} / \mathrm{ml}$. Duplicate samples were incubated for $2 \mathrm{~h}$ and $4 \mathrm{~h}$.

\section{Isolation and stimulation of human PBMCs}

Blood from healthy volunteers was collected via venipuncture directly into $K_{3}$-EDTA tubes. 15 $\mathrm{ml}$ Histopaque-1077 were pipetted into a $50 \mathrm{ml}$ conical centrifuge tube and slowly $10 \mathrm{ml}$ of blood were layered on top of each Histopaque layer. The samples were centrifuged at $400 \mathrm{x} \mathrm{g}$ for exactly $30 \mathrm{~min}$ at room temperature. The upper plasma layer was slowly aspirated with a pasteur pipet to within $0.5 \mathrm{~cm}$ from the opaque interface containing the mononuclear cells and discarded. Subsequently, the opaque interface was carefully transferred into a fresh tube avoiding carry-over of the lower Histopaque layer. $10 \mathrm{ml}$ of PBS were added and the cell suspension was gently mixed by inversion. The samples were centrifuged at $250 \mathrm{xg}$ at room temperature for $10 \mathrm{~min}$. Carefully, the supernatant was removed and discarded and the residue was re-suspended in $5 \mathrm{ml}$ PBS. The washing step was repeated twice and cells were counted using a Thoma's counting cell chamber. Finally, the cell suspension was adjusted to a final concentration of $2 \times 10^{6}$ cells per well ( 96 well plate) with RPMI 1640 supplemented with $10 \%$ fetal bovine serum (FBS) and $10 \mu \mathrm{g} / \mathrm{ml}$ Gentamicin. Following pre-incubation for 15 min with each test compound, PBMCs were stimulated with LPS ( $1 \mu \mathrm{g} / \mathrm{ml}$ LPS E.coli serotype 026:B6). After $4 \mathrm{~h}$ incubation at $37^{\circ}$ in a highly humidified atmosphere containing $5 \% \mathrm{CO}_{2}$, plates were centrifuged at $800 \mathrm{xg}$ for $6 \mathrm{~min}$ at $4{ }^{\circ} \mathrm{C}$ and TNF- $\alpha$ concentrations in the supernatants were determined by ELISA.

Cells were assayed for viability by their capacity to reduce 3-[4,5-dimethylthiazol-2-yl]-2,5diphenyltetrazolium bromide (MTT; Sigma) to MTT-formazan and none of the tested compounds showed significant cytotoxicity.

\section{Isolation and stimulation of primary mouse splenocytes}

One male and two female C57BL/6 mice (8 weeks, Synovo GmbH Tuebingen, Germany) were sacrificed, spleens were removed and homogenized in PBS. After centrifugation at $300 \mathrm{xg}$ for 10 min the cell pellets were re-suspended in DMEM (Dulbeccos's modified eagle media) supplemented with $50 \mathrm{U} / \mathrm{ml}$ of penicillin, $100 \mu \mathrm{g} / \mathrm{ml}$ of streptomycin, $0,2 \mu \mathrm{g} / \mathrm{ml}$ amphotericin B, $10 \% \mathrm{FBS}, 3 \mathrm{mM}$ L-glutamine and 50 $\mu \mathrm{M} ß$-mercaptoethanol. $1 \times 10^{6}$ cells per well were added to a 96-well, round-bottom plate and incubated overnight at $37^{\circ} \mathrm{C}\left(5 \% \mathrm{CO}_{2}\right.$ in air, $95 \%$ relative humidity). On the next day, test compounds were added and cells were pre-incubated for $15 \mathrm{~min}$ prior to stimulation with $100 \mathrm{ng} / \mathrm{ml}$ of LPS E.coli serotype 026:B6. After $18 \mathrm{~h}$ the supernatants were removed and stored frozen at $-20^{\circ} \mathrm{C}$ until determination of TNF- $\alpha$. 
Measurement of TNF- $\alpha$ concentrations by ELISA

TNF- $\alpha$ concentrations in the supernatants of whole blood and cell stimulations were measured by enzyme-linked immunosorbent assays (ELISA) according to the manufacturer's instructions. Human and porcine TNF- $\alpha$ concentrations were determined using ELISA kits from R\&D Systems (Wiesbaden, Germany). For rat and mouse TNF- $\alpha$ concentrations Biosource ELISA kits from Invitrogen (Karlsruhe, Germany) were used. Supernatants were diluted in PBS containing $1 \%$ bovine serum albumin and assayed in duplicate.

\section{Statistical evaluation}

Results are given as mean \pm S.E. mean from the number (n) of independent experiments indicated. All treatments were compared with relevant control groups. Dependent on the efficacy of the p38 MAPK inhibitors in the various test systems, corresponding $\mathrm{IC}_{50}$ values for half-maximum inhibition were calculated from concentration-inhibition curves by nonlinear regression analysis using the program GraphPad Prism (version 3.00) from GraphPad Software Inc. (La Jolla, CA, USA).

\section{Results}

Inhibition of p38 $\alpha$ MAP kinase by different inhibitors

The modulation of p38 $\alpha$ MAPK activity by five different compounds was determined in an enzyme assay measuring the inhibition of the p38 $\alpha$ MAPK mediated ATF- 2 phosphorylation. All five compounds, illustrated in Fig. 1, showed in the enzyme assay $\mathrm{IC}_{50}$ values in the low nanomolar range and are therefore considered potent inhibitors of p38 $\alpha$ MAP kinase

(Table 1). For SB 203580, the reference inhibitor, an $\mathrm{IC}_{50}$ value of $41.2 \pm 3.9 \mathrm{nM}$ was determined. This is in accordance with values determined in similar assays by Badger et al. [12] $(\sim 0.1$ $\mu \mathrm{M})$ and Trifilieff et al. [32] $(152 \pm 45 \mathrm{nM})$. With an $\mathrm{IC}_{50}$ of $2.6 \mathrm{nM}$ the Losmapimod analogue exhibited the strongest inhibition of p38 $\alpha$ MAP kinase followed by BIRB-796, CBS-3835, Pamapimod and SB 203580, in that order.

Optimization of whole blood and cellular assays

The human whole blood assay, which was established for routine screening of potential novel inhibitors used Potassium-EDTA as anti-coagulant and LPS from $E$. coli 026 :B6 at a final concentration of $1 \mu \mathrm{g} / \mathrm{ml}$. The assay protocols were previously validated by Laufer et al. [33]. In addition
Fig. 1. Chemical structures of p38 $\alpha$ MAP kinase inhibitors.

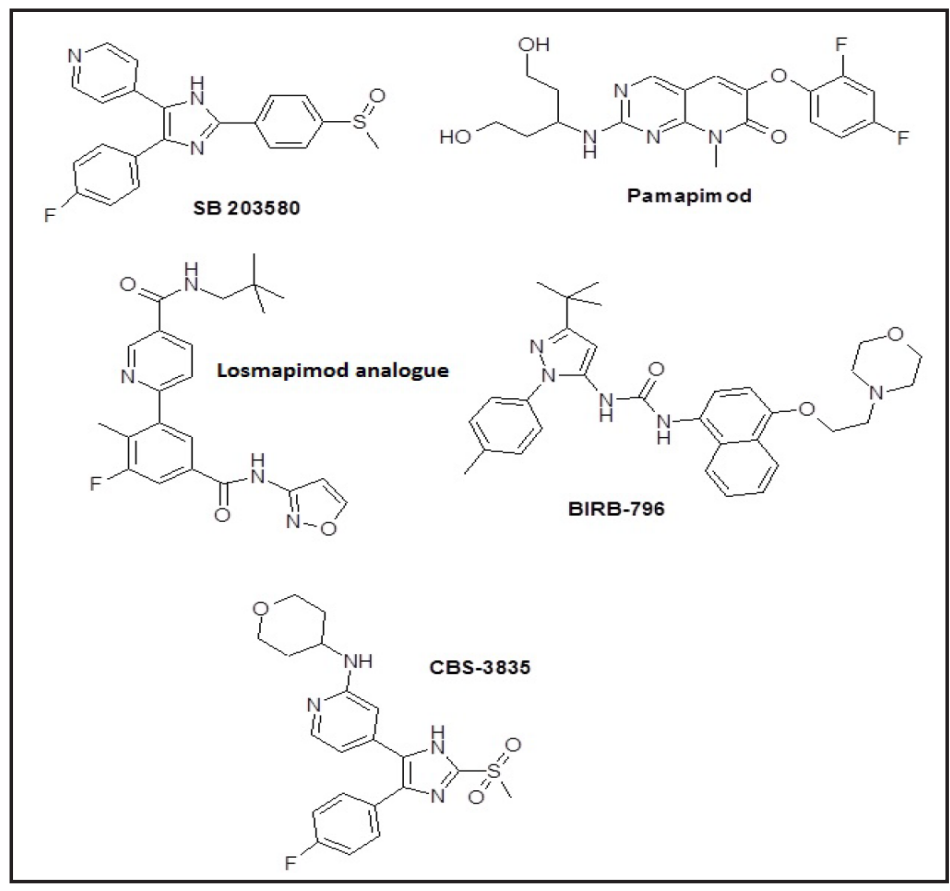

Table 1. $\mathrm{IC}_{50}$ values of selected inhibitors against p38 $\alpha$ MAPK (mean \pm S.E.M.)

\begin{tabular}{lll}
\hline Inhibitor & IC $_{50}(\mathrm{nM})$ & $\mathrm{n}$ \\
\hline \hline SB 203580 & $41.2 \pm 3.9$ & 4 \\
Losmapimod analogue & $2.6 \pm 0.3$ & 4 \\
BIRB-796 & 7.1 & 2 \\
Pamapimod & $16.5 \pm 1.0$ & 4 \\
CBS-3835 & $4.2 \pm 1.2$ & 3 \\
\hline
\end{tabular}




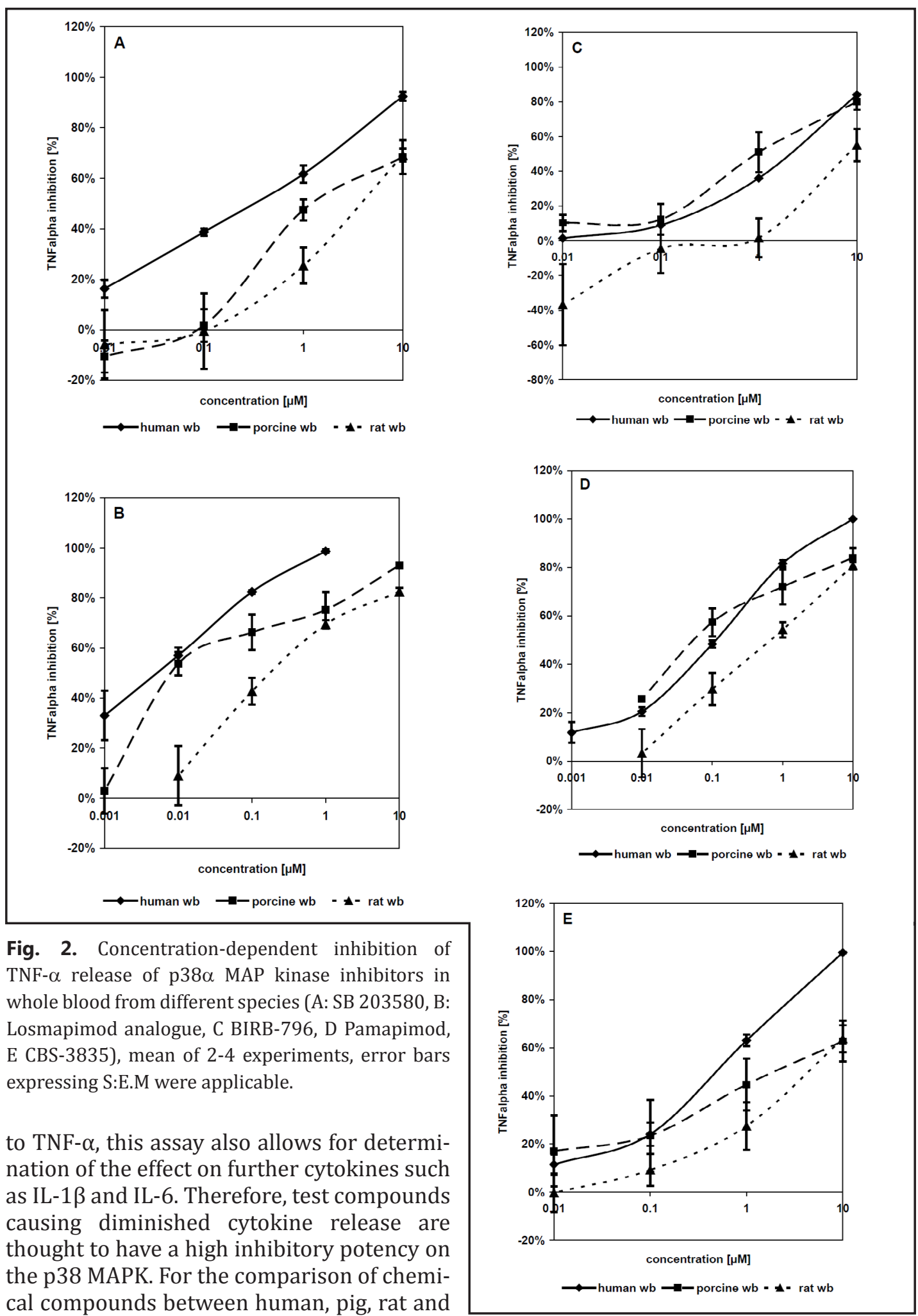

mouse the appropriate species-specific submaximal final LPS concentrations and incubation time have been determined in preliminary experiments.

Investigations on the effect of different anti-coagulants on the cytokine release demonstrated that absolute TNF- $\alpha$ concentrations were slightly higher using heparinised blood but concentration/inhibition profiles of test substances resulted in similar $\mathrm{IC}_{50}$ values KARGER 
Table 2. $\mathrm{IC}_{50}$ values (mean \pm S.E.M.) for the inhibition of TNF- $\alpha$-release in whole blood assays by $\mathrm{p} 38 \alpha \mathrm{MAPK}$ inhibitors

\begin{tabular}{lllllll}
\hline Inhibitor & $\begin{array}{l}\mathrm{IC} \mathrm{C}_{50}(\mu \mathrm{M}) \\
\text { human wb }\end{array}$ & $\mathrm{n}$ & $\begin{array}{l}\mathrm{IC}_{50}(\mu \mathrm{M}) \\
\text { porcine wb }\end{array}$ & $\mathrm{n}$ & $\begin{array}{l}\mathrm{IC}_{50}(\mu \mathrm{M}) \\
\text { rat wb }\end{array}$ & $\mathrm{n}$ \\
\hline SB 203580 & $0.35 \pm 0.07$ & 4 & $2.29 \pm 0.87$ & 4 & $3.54 \pm 0.53$ & 4 \\
Losmapimod analogue & $0.0067 \pm 0.0024$ & 4 & $0.018 \pm 0.008$ & 4 & $0.15 \pm 0.08$ & 4 \\
BIRB-796 & 1.92 & 2 & $0.93 \pm 0.57$ & 3 & $6.61 \pm 2.77$ & 4 \\
Pamapimod & $0.11 \pm 0.01$ & 4 & $0.069 \pm 0.016$ & 3 & $0.70 \pm 0.21$ & 4 \\
CBS-3835 & $0.47 \pm 0.07$ & 4 & $4.76 \pm 1.36$ & 4 & $2.44 \pm 0.39$ & 4 \\
\hline
\end{tabular}

Table 3. $\mathrm{IC}_{50}$ values (mean \pm S.E.M.) for the inhibition of TNF- $\alpha$-release in primary cell cultures by $\mathrm{p} 38 \alpha$ MAPK inhibitors

\begin{tabular}{llllr}
\hline Inhibitor & $\begin{array}{l}\text { IC } 50(\mu \mathrm{M}) \\
\text { human PBMC }\end{array}$ & $\mathrm{n}$ & $\begin{array}{l}\mathrm{IC}_{50}(\mu \mathrm{M}) \\
\text { mouse splenocytes }\end{array}$ & $\mathrm{n}$ \\
\hline \hline SB 203580 & 0.43 & 2 & $2.22 \pm 1.06$ & 3 \\
Losmapimod analogue & 0.059 & 2 & $<0.010$ & 2 \\
BIRB-796 & 0.083 & 2 & $0.034 \pm 0.012$ & 3 \\
Pamapimod & 0.32 & 2 & $0.21 \pm 0.10$ & 3 \\
CBS-3835 & 0.37 & 2 & $3.24 \pm 1.47$ & 3 \\
\hline
\end{tabular}

(unpublished data). Dilution with PBS facilitated the screening of twice as many compounds with the same amount of blood without having a significant impact on cytokine production and inhibition. For evaluation of the effect of test substances, results were accepted if the TNF- $\alpha$ concentrations in negative controls remained below $20 \mathrm{pg} / \mathrm{ml}$ while in positive controls (LPS without test substance), a TNF- $\alpha$ concentration of $>100 \mathrm{pg} / \mathrm{ml}$ was required.

For all animal species, heparinized blood was used instead of Potassium-EDTA blood. In a preliminary experiment porcine whole blood was stimulated with $1 \mu \mathrm{g} / \mathrm{ml}$ LPS derived from two different $E$. coli serotypes (026:B6 and 0111:B4). Since TNF- $\alpha$ levels detected in plasma were clearly below $100 \mathrm{pg} / \mathrm{ml}$ a higher LPS concentration of $25 \mu \mathrm{g} / \mathrm{ml}$ was selected to achieve TNF- $\alpha$ levels similar to levels seen in the human whole blood assay [34]. TNF- $\alpha$ stimulation with LPS from E. coli serotype 0111:B4 was always more effective compared to serotype 026:B6 (data not shown).

Likewise, stimulation of rat whole blood with $1 \mu \mathrm{g} / \mathrm{ml}$ LPS E. coli serotype 026:B6 only produced low TNF- $\alpha$ levels below $100 \mathrm{pg} / \mathrm{ml}$ plasma. An additional experiment using different concentrations of LPS E. coli serotype 026:B6 and LPS Salmonella enterica serotype abortus equi demonstrated that rat whole blood was more sensitive to stimulation with LPS from Salmonella enterica releasing at least twice as much TNF- $\alpha$ compared to stimulation with LPS form E. coli. For ongoing experiments, a final concentration of $10 \mu \mathrm{g} / \mathrm{ml}$ and an incubation time of $2 \mathrm{~h}$ proved adequate to achieve TNF- $\alpha$ levels comparable to the human whole blood assay (data not shown).

Due to the limited availability of mouse whole blood and the high variability in TNF- $\alpha$ production seen in preliminary experiments, for ethical reasons, it was decided to use mouse splenocytes instead of mouse whole blood.

Assays with human PBMCs and mouse splenocytes were performed according to previously validated protocols [35]. An appropriate stimulation of TNF- $\alpha$ release in mouse splenocytes was achieved after $4 \mathrm{~h}$ with LPS from $E$. coli serotype 026:B6 (final concentration $100 \mathrm{ng} / \mathrm{ml}$ ).

Inhibition of LPS-stimulated TNF- $\alpha$ release in different species

Fig. 2 illustrates the concentration/response curves of all five p38 $\alpha$ MAPK inhibitors in LPS-stimulated whole blood from humans, pigs and rats. Corresponding $\mathrm{IC}_{50}$ values, which 
were derived from these curves calculated by nonlinear regression, are summarized in Table 2. Moreover, Table 3 presents $I_{50}$ values, which were generated from experiments in human PBMCs and mouse splenocytes.

The concentration/response curves illustrate, that the most efficient inhibition, relative to positive controls, was observed with human whole blood. At the highest test concentrations, the maximum inhibition of TNF- $\alpha$ release varied between $85 \%$ (BIRB-796) and $100 \%$ (Losmapimod analogue, Pamapimod and CBS-3835). With porcine whole blood, the maximum inhibition varied between $63 \%$ (CBS-3835) and $93 \%$ (Losmapimod analogue) and the lowest relative inhibition was observed with rat whole blood (55 \% - $83 \%$ ).

Surprisingly, the five different p38 MAPK inhibitors revealed tremendous interspecies differences. For example, the Losmapimod analogue (Fig. 2B) exhibited IC ${ }_{50}$ values in the low nanomolar range for human whole blood $(0.007 \mu \mathrm{M})$, human PBMCs $(0.0032 \mu \mathrm{M})$, porcine whole blood $(0.018 \mu \mathrm{M})$ and mouse splenocytes $(<0.01 \mu \mathrm{M})$. In contrast, less potency was observed in rat whole blood ( $\mathrm{IC}_{50}$ value $\left.0.15 \mu \mathrm{M}\right)$.

Pamapimod (Fig. 2D) was the most balanced inhibitor with a maximum 10-fold difference between $\mathrm{IC}_{50}$ values of porcine $(0.069 \mu \mathrm{M})$ and rat whole blood $(0.70 \mu \mathrm{M})$. In this range, human whole blood $(0.11 \mu \mathrm{M})$, human PBMCs $(0.18 \mu \mathrm{M})$ and mouse splenocytes $(0.21$ $\mu \mathrm{M}$ ) were equipotent.

Additionally, all investigated species showed similar inhibition profiles for the imidazole-based p38 $\alpha$ MAP kinase inhibitors SB 203580 (Fig. 2A) and CBS-3835 (Fig. 2E), although SB 203580 was less potent in the p38 MAPK enzyme assay compared to CBS-3585. Both compounds were most effective in human whole blood with a half maximum inhibition of $0.35 \mu \mathrm{M}$ (SB 203580) and $0.47 \mu \mathrm{M}$ (CBS-3835). Conversely, in rat and porcine whole blood as well as mouse splenocytes, concentrations in the low micromolar range were necessary for both compounds to achieve $50 \%$ inhibition.

Interestingly, BIRB-796 demonstrated significant differences between blood and cellbased assays. In human PBMCs an $\mathrm{IC}_{50}$ value of $0.0074 \mu \mathrm{M}$ was calculated which is 260 -fold more potent when compared to human whole blood $(1.92 \mu \mathrm{M})$. BIRB-796 was also clearly less effective in blocking TNF- $\alpha$ production in porcine $(0.93 \mu \mathrm{M})$ and rat $(6.61 \mu \mathrm{M})$ whole blood, respectively, in comparison to $\mathrm{IC}_{50}$ results obtained from mouse splenocytes $(0.034$ $\mu \mathrm{M})$.

In summary, comparing the effects of the different p38 MAPK inhibitors in whole blood and primary cells from rats, mice, pigs and humans, the highest $\mathrm{IC}_{50}$ values always came from rat whole blood, where inhibitors showed 6-fold (Pamapimod) to 25-fold (Losmapimod analogue) less efficacy compared to human whole blood. Strongest TNF- $\alpha$ inhibition was generally achieved in human PBMCs and human whole blood indicating that only human test systems can predict reliably the inhibitory potential of p38 MAPK inhibitors.

\section{Discussion}

The aim of the present work was to investigate the anti-inflammatory activity of a group of chemically distinct p38 $\alpha$ MAPK with regard to the inhibition of TNF- $\alpha$ release in whole blood and primary cells from different species.

The five selected test compounds (SB 203580, BIRB-796, Pamapimod, a Losmapimod analogue and CBS-3835) all inhibited p38 $\alpha$ MAP kinase in an enzyme assay at low nanomolar concentrations. Previously published $\mathrm{IC}_{50}$ values of $136 \mathrm{nM}$ for SB 203580 (Brown et al.) [36], $14 \mathrm{nM}$ for Pamapimod (Hill et al.) [14] and $20 \mathrm{nM}$ for BIRB-796 (Ross et al.) [37] are in the range with our results. In addition Hill et al. [14] reported an $\mathrm{IC}_{50}$ of $400 \mathrm{nM}$ for the inhibition of TNF- $\alpha$ from whole blood by Pamapimod, which is in line with our results demonstrating the validity of our assay.

Until now, an in depth species comparison of the in vitro cellular activities has not been reported for p38 $\alpha$ MAPK. Since whole blood provides a more protein and cell-rich milieu than PBMCs, we selected whole blood as the most appropriate in vitro system for 
the determination of monocytic cytokine production taking into account physiological proportions. For comparison, we also performed assays with human PBMCs.

The use of human whole blood cultures is regarded as a valid approach for the investigation of the modulation of cytokine production by anti-inflammatory compounds as demonstrated by Damsgaard et al. [38] albeit the experimental protocols published by different authors vary in terms of selected anti-coagulant, LPS subtype, concentration and incubation. These experimental conditions however, may significantly influence assay results. Duvigneau et al. [39] reported that Heparin and EDTA differentially affected cytokine mRNA levels of cultured porcine blood when used as anticoagulants. Heparin was also associated with an enhanced cytokine production e.g. by binding to LPS-binding protein (Call and Remick [40]; Heinzelmann and Bosshart [41] ). In addition, genetic differences may also influence the production of TNF- $\alpha$, e.g. Louis and colleagues [42] reported, that TNF- $\alpha$ gene polymorphisms alter TNF- $\alpha$ synthesis in healthy humans after stimulation with LPS. In addition, Aulock et al. [43] observed a difference in the sensitivity to LPS stimulation between healthy male and female volunteers with blood from males producing more TNF- $\alpha$ than blood from females

As a starting point, we used our validated in-house protocol for a human whole blood cytokine assay. This assay uses $\mathrm{K}_{3}$-EDTA as anticoagulant and LPS from E. coli serotype 026:B6 at $1 \mu \mathrm{g} / \mathrm{ml}$ for stimulation of TNF- $\alpha$ secretion for $4 \mathrm{~h}$. When we applied this protocol to whole blood from other species, TNF- $\alpha$ production was significantly lower compared to human blood. A poor response to LPS challenge in comparison with human whole blood was also described by Dietsch et al. [44] for rat whole blood as well as by Foster et al. [45] when using mouse whole blood.

The innate immune response triggered by LPS is mediated by toll-like receptor 4 (TLR4). Thus, the reason for this species difference in sensitivity to LPS may be related to a different expression of this receptor as well as functional differences in the recognition of LPS. Since an in-depth investigation of the influence of the anticoagulant as well as the LPS serotype and concentration in order to elucidate the cause of the different responses was beyond our scope, we tried to optimize the experimental conditions for each species to achieve comparable TNF- $\alpha$ levels allowing for the screening of test compounds.

Using PBMCs from humans, rats and Beagle dogs, Wadsworth et al. [16] reported species differences for the p38 $\alpha$ MAPK inhibitors SB 203580 and RWJ 67657 in the inhibition of TNF- $\alpha$ release. For both compounds, the rat PBMC response was about 90 -fold less sensitive compared to the response in human PBMCs, which is in agreement with our whole blood findings. In PBMCs from Beagle dogs, the sensitivity was only about 2- to 3-fold lower in comparison with human PBMCs. The IC $_{50}$ of 45 nM determined for SB 203580 in human PBMCs however, is clearly lower compared to our results.

So far, there is no reference data available for porcine whole blood as an in vitro test system for p38 $\alpha$ MAPK inhibitors. With the selected inhibitors, controversial results were obtained showing either lower or equal potency compared to human whole blood. The reason for this finding is not clear and may need further investigation.

The most striking results however were obtained for BIRB-796, the only non-ATP competitive inhibitor investigated. BIRB-796 only showed weak inhibition of LPS-challenged TNF- $\alpha$ release in whole blood, but proved very effective in the less protein-rich milieu of human PBMCs. Such a large difference was not seen for any other compound since $\mathrm{IC}_{50}$ values determined in human whole blood and human PBMCs were always in the same range. Whether this is related to different physico-chemical properties of BIRB-796 or to its unique binding mode needs to be further elucidated. However, this finding is in line with previously published results. Cogan et al. [46] demonstrated an $\mathrm{IC}_{50}$ for $780 \mathrm{nM}$ for BIRB-796 in human whole blood in contrast to an $\mathrm{IC}_{50}$ of $7.6 \mathrm{nM}$ found in human PBMCs by Gruenbaum et al. [47]. Hence, caution needs to be exercised when interpreting data from whole blood assays and assays performed with primary cells. BIRB-796 also demonstrated excellent efficacy in mouse splenocytes, which probably more resemble the primary cultures of human PBMC. 
In contrast, for all other compounds the inhibition in human PBMCs and mouse splenocytes was not comparable.

There is also little knowledge whether and how species differences seen in in vitro models translate into differences in vivo. For PDE4 inhibitors, the highest functional sensitivity towards the inhibition of TNF- $\alpha$ release from leukocytes was demonstrated in rats followed by monkeys and humans [48]. The authors concluded that these differences might be responsible for the higher susceptibility of rats to toxicity induced by PDE4 inhibitors since they demonstrated significantly higher mRNA levels in toxicologically relevant tissues from rats in comparison with human tissue.

Rats and mice are also routinely used for in vivo pharmacology studies as well as toxicity studies in the case of p38 $\alpha$ MAPK inhibitors. According to our results, the ability of p38 $\alpha$ MAPK inhibitors to modulate monocytic TNF- $\alpha$ production ex vivo varies with different species even though the order of potency of different inhibitors generally remained constant between the different species. Thus, a thorough investigation of the expression and functional sensitivity of $\mathrm{p} 38 \alpha$ MAPK in the different species may facilitate prediction of efficacy and toxicity in humans based on results from in vitro and animal studies.

Taken together, the potency of p38 $\alpha$ MAPK inhibitors to modulate TNF- $\alpha$ release after LPS-challenge in rat whole blood is clearly lower compared to human whole blood. In addition, higher LPS concentrations are necessary to obtain similar TNF- $\alpha$ production in animal-derived blood. Based on $\mathrm{IC}_{50}$ values, in rat whole blood, a 3.4-fold (BIRB-796) to 22fold (Losmapimod analogue) higher concentration was necessary to achieve the same TNF- $\alpha$ suppressive activity as observed in human whole blood. Differences between porcine whole blood and human whole blood were less pronounced. Caution also needs to be taken when comparing results from whole blood assays and assays using primary cell cultures. Further investigations are required to assess the relevance of these species-specific differences for allometric scaling of the pharmacokinetics and pharmacodynamics of p38 MAPK inhibitors and to estimate the human doses required to achieve a clinical response.

\section{Disclosure Statement}

The authors had no conflicts of interest to declare in relation to this article.

\section{Acknowledgements}

This work was supported by the European Union FP7 “Kinacept” project (\# 222509), the ICEPHA (Interfaculty Center for Pharmacogenomics and Drug Research) grant and in part by the Robert Bosch Stiftung, Stuttgart, Germany.

\section{References}

1 Lee JC, Laydon JT, McDonnell PC, Gallagher TF, Kumar S, Green D: A protein kinase involved in the regulation of inflammatory cytokine biosynthesis. Nature 1994;372:739-746

2 Kumar S, Boehm J, Lee JC: p38 MAP kinases: Key signalling molecules as therapeutic targets for inflammatory diseases. Nat Rev Drug Discov 2003;2:717-726

3 Korb A, Tohidast-Akrad M, Cetin E, Axmann R, Smolen J, Schett G: Differential tissue expression and activation of p38 MAPK alpha, beta, gamma, and delta isoforms in rheumatoid arthritis. Arthritis Rheum 2006;54:2745-56.

4 Waetzig GH, Seegert D, Rosenstiel P, Nikolaus S, Schreiber S: p38 mitogen-activated protein kinase is activated and linked to TNF-alpha signaling in inflammatory bowel disease. J Immunol 2002;15:53425351. 


\section{Cellular Physiology Cell Physiol Biochem 2015;36:2237-2249

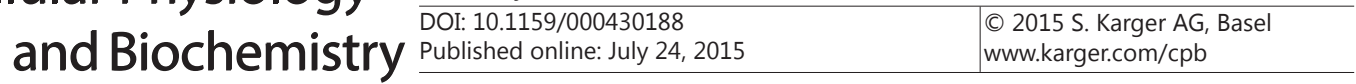

Fehr et al.: Species-Specific Cell Assays for p38 MAPK Inhibitor Testing

5 Renda T, Baraldo S, Pelaia G, Bazzan E, Turato G, Papi A, Maestrelli P, Maselli R, Vatrella A, Fabbri LM, Zuin R, Marsico SA, Saetta M: Increased activation of p38 MAPK in COPD. Eur Respir J 2008;31:62-69.

6 Meng Z, Yan C, Deng Q, Dong X, Duan ZM, Gao DF, Niu XL. Oxidized low-density lipoprotein induces inflammatory responses in cultured human mast cells via Toll-like receptor 4. Cell Physiol Biochem 2013;31:842-853.

7 Yang Y, Lian YT, Huang SY, Yang Y, Cheng LX, Liu K: GABA and topiramate inhibit the formation of human macrophage-derived foam cells by modulating cholesterol-metabolism-associated molecules. Cell Physiol Biochem 2014;33:1117-1129.

8 Borst O, Walker B, Münzer P, Russo A, Schmid E, Faggio C, Bigalke B, Laufer S, Gawaz M, Lang F. Skepinone-L, a novel potent and highly selective inhibitor of p38 MAP kinase, effectively impairs platelet activation and thrombus formation. Cell Physiol Biochem 2013;31:914-924.

9 Tang W, Lv Q, Chen XF, Zou JJ, Liu ZM, Shi YQ: CD8(+) T cell-mediated cytotoxicity toward Schwann cells promotes diabetic peripheral neuropathy. Cell Physiol Biochem 2013;32:827-837.

10 Hosokawa Y, Hosokawa I, Shindo S, Ozaki K, Matsuo T: (-)-Epigallocatechin-3-gallate inhibits CC chemokine ligand 11 production in human gingival fibroblasts. Cell Physiol Biochem 2013;31:960-967.

11 Shieh JM, Tsai YJ, Tsou CJ, Wu WB: CXCL1 regulation in human pulmonary epithelial cells by tumor necrosis factor. Cell Physiol Biochem 2014;34:1373-1384.

12 Chen J, Liao MY, Gao XL, Zhong Q, Tang TT, Yu X, Liao YH, Cheng X: IL-17A induces pro-inflammatory cytokines production in macrophages via MAPKinases, NF- $\kappa$ B and AP-1. Cell Physiol Biochem 2013;32:1265-1274.

13 Sweeney SE: The as-yet unfulfilled promise of p38 MAPK inhibitors. Nat Rev Rheumatol 2009;5:475-77.

14 Goldstein DM, Kuglstatter A, Lou Y, Soth MJ: Selective p38 $\alpha$ Inhibitors clinically evaluated for the treatment of chronic inflammatory disorders. J Med Chem 2010;53:2345-2353.

15 Cohen SB, Cheng TT, Chindalore V, Damjanov N, Burgos-Vargas R, Delora P, Zimany K, Travers H, Caulfield JP: Evaluation of the efficacy and safety of pamapimod, a p38 MAP kinase inhibitor, in a double-blind, methotrexate-controlled study of patients with active rheumatoid arthritis. Arthritis Rheum 2009;60:335344.

16 Laufer S, Thuma S, Peifer C, Greim C, Herweh Y, Albrecht A, Dehner F: An immunosorbent, nonradioactive p38 MAP kinase assay comparable to standard radioactive liquid-phase assays. Anal Biochem 2005;344:135-137.

17 Laufer S, Greim C, Luik S, Ayoub SS, Dehner F: Human whole blood assay for rapid and routine testing of non-steroidal anti-inflammatory drugs (NSAIDs) on cyclo-oxygenase-2 activity. Inflammopharmacology 2008;16:155-161.

18 Hope HR, Anderson GD, Burnette BL, Compton RP, Devraj RV, Hirsch JL, Keith RH, Li X, Mbalaviele G, Messing DM, Saabye MJ, Schindler JF, Selness SR, Stillwell LI, Webb EG, Zhang J, Monahan JB: Antiinflammatory properties of a novel N-phenyl pyridinone inhibitor of p38 mitogen-activated protein kinase: preclinical-to-clinical translation. J Pharmacol Exp Ther 2009;331:882-895.

19 Badger AM, Bradbeer JN, Votta B, Lee JC, Adams JL, Griswold DE: Pharmacological profile of SB 203580, a selective inhibitor of cytokine suppressive binding protein/p38 kinase, in animal models of arthritis, bone resorption, endotoxin shock and immune function. J Pharmcol Exp Ther 1996;279:1453-1461.

20 Medicherla S, Ma JY, Mangadu R, Jiang Y, Zhao JJ, Almirez R, Kerr I, Stebbins EB, O’Young G, Kapoun AM, Luedtke G, Chakravarty S, Dugar S, Genant HK, Protter AA: A selective p38 $\alpha$ mitogen-activated protein kinase inhibitor reverses cartilage and bone destruction in mice with collagen-induced arthritis. J Pharmacol Exp Ther 2006;318:132-141.

21 Hill RJ, Dabbagh K, Phippard D, Li C, Suttmann RT, Welch M, Papp E, Song KW, Chang KC, Leaffer D, Kim YN, Roberts RT, Zabka TS, Aud D, Dal Porto J, Manning AM, Peng SL, Goldstein DM, Wong BR: Pamapimod, a novel p38 mitogen-activated protein kinase inhibitor: preclinical analysis of efficacy and selectivity. J Pharmacol Exp Ther 2008;327:610-619.

22 Zhang X, Huang Y, Navarro MT, Hisoire G, Caulfield JP: A proof-of-concept and drug-drug interaction study of pamapimod, a novel p38 MAP kinase inhibitor, with methotrexate in patients with rheumatoid arthritis. J Clin Pharmacol 2010;50:1031-1038.

23 Wadsworth SA, Cavender DE, Beers SA, Lalan P, Schafer PH, Malloy EA, Wu W, Gahmy B, Olini GC, Davis JE, Pellegrino-Gensey JL, Wachter MP, Siekierka JJ: RWJ 67657, a potent, orally active inhibitor of p38 mitogenactivated protein kinase. J Pharmacol Exp Ther 1999;291:680-687. 


\section{Cellular Physiology Cell Physiol Biochem 2015;36:2237-2249 \begin{tabular}{l|l|l}
\hline DOI: 10.1159/000430188 & C 2015 S. Karger AG, Basel
\end{tabular} and Biochemistry Published online: July 24, 2015 \\ Fehr et al.: Species-Specific Cell Assays for p38 MAPK Inhibitor Testing}

24 Lee JC, Kassis S, Kumar S, Badger A, Adams JL: p38 mitogen-activated protein kinase inhibitors mechanisms and therapeutic potentials. Pharmacol Ther 1999;82:389-397.

25 Yang S, Lukey P, Beerahee M, Hoke F: Population pharmacokinetics of losmapimod in healthy subjects and patients with rheumatoid arthritis and chronic obstructive pulmonary diseases. Clin Pharmacokinet 2013;52:187-198.

26 Watz H, Barnacle H, Hartley BF, Chan R: Efficacy and safety of the p38 MAPK inhibitor losmapimod for patients with chronic obstructive pulmonary disease: a randomised, double-blind, placebo-controlled trial. Lancet Respir Med 2014;2:63-72.

27 Dewenter M, Vettel C, El-Armouche A: Losmapimod: a novel drug against cardiovascular diseases. Dtsch Med Wochenschr 2013;138:39-42.

28 Ostenfeld T, Krishen A, Lai RY, Bullman J, Baines AJ, Green J, Anand P, Kelly M: Analgesic efficacy and safety of the novel p38 MAP kinase inhibitor, losmapimod, in patients with neuropathic pain following peripheral nerve injury: a double-blind, placebo-controlled study. Eur J Pain 2013;17:844-857.

29 Pargellis C, Tong L, Churchill L, Cirillo PF, Gilmore T, Graham AG, Grob PM, Hickey ER, Moss N, Pav S, Regan J: Inhibition of p38 MAP kinase by utilizing a novel allosteric binding site. Nat Struct Biol 2002;9:268-272.

30 Regan J, Capolino A, Cirillo PF, GilmoreT, Graham AG, Hickey E, Kroe RR, Madwed J, Moriak M, Nelson R, Pargellis CA, SwinamerA, TorcellinC, Tsang M, Moss N: Structure-Activity Relationships of the p38alpha MAP Kinase Inhibitor 1-(5-tert-Butyl-2-p-tolyl-2H-pyrazol-3-yl)-3-[4-(2morpholin-4-yl-ethoxy)naphthalen-1-yl]urea (BIRB 796). J Med Chem 2003;46:4676-4686.

31 Doggrell SA, Christensen AM: Does the p38 MAP kinase inhibitor pamapimod have potential for the treatment of rheumatoid arthritis? Expert Opin Pharmacother 2010;11:2437-42.

32 Trifilieff A, Keller TH, Press NJ, Howe T, Gedeck P, Beer D, Walker C: CGH2466, a combined adenosine receptor antagonist, p38 mitogen-activated protein kinase and phosphodiesterase type 4 inhibitor with potent in vitro and in vivo anti-inflammatory activities. Br J Pharmacol 2005;144:1002-1010.

33 Laufer S, Greim C, Bertsche T: An in-vitro screening assay for the detection of inhibitors of proinflammatory cytokine synthesis: a useful tool for the development of new antiarthritic and disease modifying drugs. Osteoarthritis Cartilage 2002;10:961-967.

34 Carstensen L, Rontved CM, Nielsen JP: Determination of tumor necrosis factor-alpha responsiveness in piglets around weaning using an ex vivo whole blood stimulation assay. Vet Immunol Immunopathol 2005;105:59-66.

35 Laufer S, Greim C, Bertsche T: An in-vitro screening assay for the detection of inhibitors of proinflammatory cytokine synthesis: a useful tool for the development of new antiarthritic and disease modifying drugs. Osteoarthritis Cartilage 2002;10:961-967.

36 Brown KK, Heimeyer SA, Hookfin EB, Hsieh L, Buchalova M, Taiwo YO, Janusz MJ: p38 MAP kinase inhibitors as potential therapeutics for the treatment of joint degeneration and pain associated with osteoarthritis. J Inflamm 2008;5:22.

37 Ross S, Chen T, Yu V, Tudor Y, Zhang D, Liu L, Tamayo N, Dominguez C, Powers D: High-content screening analysis of the p38 pathway: profiling of structurally related p38 $\alpha$ kinase inhibitors using cell-based assays. Assay Drug Dev Technol 2006;4:397-409.

38 Damsgaard CT, Lauritzen L, Calder PC, Kjaer TM, Frokiaer H: Whole-blood culture is a valid low-cost method to measure monocytic cytokines - a comparison of cytokine production in cultures of human whole-blood, mononuclear cells and monocytes. J Immunol Methods 2009;340:95-101.

39 Duvigneau JC, Sipos W, Hartl RT, Bayer M, Moldzio R, Stevenson L, Adair B, Gemeiner M: Heparin and EDTA as anticoagulant differentially affect cytokine mRNA level of cultured porcine blood cells. J Immunol Methods 2007;324:38-47.

40 Call DR, Remick DG: Low molecular weight heparin is associated with greater cytokine production in a stimulated whole blood model. Shock 1998;10:192-197.

41 Heinzelmann M, Bosshart H: Heparin binds to lipopolysaccharide (LPS)-binding protein, facilitates the transfer of LPS to CD14, and enhances LPS-induced activation of peripheral blood monocytes. J Immunol 2005;174:2280-2287.

42 Louis E, Franchimont D, Piron A, Gevaert Y, Schaaf-Lafontaine N, Roland S, Mahieu P, Malaise M, De Groote D, Louis R, Belaiche J: Tumour necrosis factor (TNF) gene poymorphism influences TNF-alpha production in lipopolysaccharide (LPS)-stimulated whole blood cell culture in healthy humans. Clin Exp Immunol 1998;113:401-406. 


\section{Cellular Physiology Cell Physiol Biochem 2015;36:2237-2249

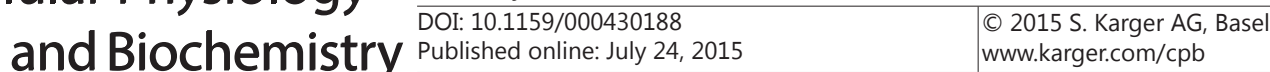 \\ Fehr et al.: Species-Specific Cell Assays for p38 MAPK Inhibitor Testing}

43 Aulock SV, Deininger S, Draing C, Gueinzius K, Dehus O, Hermann C: Gender difference in cytokine secretion on immune stimulation with LPS and LTA. J Interferon Cytokine Res 2006;26:887-892.

44 Dietsch GN, Dipalma CR, Eyre RJ, Pham TQ Poole KM, Pefaur NB, Welch WD, Trueblood E, Kerns WD, Kanaly ST: Characterization of the inflammatory response to a highly selective PDE4 inhibitor in the rat and the identification of biomarkers that correlate with toxicity. Toxicol Pathol 2006;34:39-51.

45 Foster SJ, McCormick LM, Ntolosi BA, Campbell D: Production of TNF $\alpha$ by LPS-stimulated murine, rat and human blood and its pharmacological modulation. Agents Actions 1993;38:77-79.

46 Cogan DA, Aungst R, Breinlinger EC, Fadra T, Goldberg DR, Hao MH, Kroe R, Moss N, Pargellis C, Qian KC, Swinamer AD: Structure-based design and subsequent optimization of 2-tolyl-(1,2,3-triazol-1-yl-4carboxamide) inhibitors of p38 MAP kinase. Bioorg Med Chem Lett 2008;18:3251-3255.

47 Gruenbaum LM, Schwartz R, Woska JR, DeLeon RP, Peet GW, Warren TC, Capolino A, Mara L, Morelock MM, Shrutkowski A, Jones JW, Pargellis CA: Inhibition of pro-inflammatory cytokine production by the dual p38/JNK2 inhibitor BIRB-796 correlates with the inhibition of p38 signaling. Biochem Pharmacol 2009;77:422-432.

48 Bian H, Zhan J, Wu P, Varty LA, Jia Y, Mayhood T, Hey JA, Wang P: Differential type 4 cAMP-specific phosphodiesterase (PDE4) expression and functional sensitivity to PDE4 inhibitors among rats, monkeys and humans. Biochem Pharmacol 2004;68:2229-2236. 